\title{
Ethics in economics: lessons from human subjects research
}

\author{
MEGAN BLOMFIELD \\ University of Bristol
}

\begin{abstract}
Many economists, it is said, "are inclined to deny that moral philosophy has anything to do with economics" (Hausman and McPherson 2006, 291). In this paper I challenge such inclinations by drawing an analogy between economic interventions and human subjects research. It is undeniable that investigators engaged in the latter should adhere to specific ethical principles. I argue that analogous features of economic interventions should lead us to recognise that similar ethical concerns actually arise in both activities, and thus that economic interventions should also be conducted in accordance with ethical principles. By exploring the analogy further I formulate some ethical guidelines for economic practice, which in turn imply that ethical responsibilities will extend to all members of the economics profession.
\end{abstract}

Keywords: experimental economics, positive-normative distinction, research ethics

JEL Classification: A13, B40, B41, C90

It is said that "many economists are inclined to deny that moral philosophy has anything to do with economics" (Hausman and McPherson 2006, 291). Whether this accusation is entirely fair can be questioned, ${ }^{1}$ but there is some agreement that the belief that economics

\footnotetext{
${ }^{1}$ DeMartino-an economist who is very concerned with ethics-gives evidence that economists are often acutely aware of the moral quandaries that their profession may place them in (DeMartino 2011, chapter 3). The position DeMartino defends in his book is similar to mine in many respects, but our approaches differ somewhat. His work builds a strong and extensive case for a professional code of ethics for economists, grounded in the influence that economists enjoy, their institutional power, the harm that economic interventions can do, and the uncertainty under which

AUTHOR's NoTE: This article was originally written for a course I took at the University of Toronto with Jossi Berkovitz, for whose instruction I am very grateful. I would also like to thank George DeMartino, one anonymous referee of this journal, and editor Thomas Wells for extensive and constructive comments. They helped me to address a fundamental flaw that appeared in the original version and identified various other places where important revisions were needed.
} 
is an objective science, "insulated from ethics", is widely held in the profession and "continues to inform economic training and practice" (DeMartino 2011, 70, 62). This understanding of economics enables economists to argue that, even when they are called on to give policy advice, their scientific input can be value-free "provided the means-ends distinction is rigidly maintained" (Blaug 1992, 129); in other words, provided that it is governments or policymakers that decide on the goals of the policy, and the economist's involvement is restricted to the provision of objective information about options for achieving those goals. As Per Pinstrup-Andersen-an economics professor at Cornell University-relates: "I was trained to believe that economists are supposed to do value-free, positive policy analysis and leave the normative part to the policymaker" (Pinstrup-Andersen 2005, 1097).

In this paper I will be challenging this understanding of economics by arguing that there is an important class of normative questions that should be the concern of all economists-questions of how to practice ethically within their field. Positive and normative economists alike seek to understand or influence real-world economic systems. ${ }^{2}$ There is immediate potential for ethical concerns to arise here because human beings are an essential part of these real-world economic systems. To see where such concerns materialise, I start by discussing one area of economic research where it is indisputable that economists need to follow certain ethical guidelines-research involving human subjects. I argue that anyone who accepts the significance of ethical concerns in human subjects research must acknowledge that analogous ethical concerns arise in all economic interventions. I then discuss what responsibilities economists, in particular, will bear in relation to such ethical concerns; for this I use a brief discussion of the lessons that can be learned from clinical research ethics to investigate how far within the economics profession the need to adhere to ethical standards extends. I conclude that economics cannot and should not be considered value-free.

economists operate (DeMartino 2011, 116). I also identify some of these aspects of economic practice as being important. However, instead of employing them directly as a ground for economic ethics, I use them to develop an analogy between economic practice and human subjects research. This analogy is intended to persuade those who acknowledge the existence of ethical concerns in the latter activity that they cannot consistently deny their presence in the former. Insights that I have gained from DeMartino's book have undoubtedly helped to clarify and strengthen my arguments.

2 I am assuming that economists are in fact interested in real-world economic systems. Those who are not seem more appropriately classed as mathematicians or philosophers. 


\section{EXPERIMENTAL ECONOMICS}

Economists have increasingly been turning to experimental methods in their pursuit of knowledge. Laboratory experiments have been used in economics since at least the 1930s (Roth 1993, 184-185). What I will be concentrating on in this section, however, is the growing use of field experiments in economic research.

A field experiment is an experiment conducted on a system of interest in its natural environment. In economics such experiments are generally thought to have been pioneered by the 1967 New Jersey Income Maintenance experiment (Ferber and Hirsch 1978, 1380; Greenberg, et al. 1999, 158). Field experiments are designed to measure the effects of changes in economic policy "by applying these changes to human populations under conditions of controlled experimentation similar to that used in the physical and biological sciences". Effectively, this involves using "the real world as a laboratory" (Ferber and Hirsch 1978, 1379-1380).

Economic field experiments have been particularly popular in the United States, where economists play "a major role in designing, operating, and evaluating social experiments" (Greenberg, et al. 1999, 170). More recently, development economists have been turning to such experimentation and as a result there is "a growing methodology for analysing micropolicy questions in randomised controlled trials (also known as Randomized Evaluations, REs)" (Cohen and Easterly 2009, 1; see also Banerjee and Duflo 2009, 152).

Social experiments, involving as they do "the manipulation of people's resources and even life styles", clearly raise ethical questions (Ferber and Hirsch 1978, 1395). To see just how important these questions can be, consider an example of one of the REs that are becoming popular in development economics. This study, conducted by Jessica Cohen and Pascaline Dupas, was designed to test the hypothesis that "cost-sharing-charging a subsidized, positive price-for a health product is necessary to avoid wasting resources on those who will not use or do not need the product" (Cohen and Dupas 2010, 1). This hypothesis is based on economic theories implying three potential effects of positive pricing. Firstly, positive pricing may give rise to a selection effect, allocating the product to those who value-or need-it the most. Additionally, it is claimed that paying for a product encourages an individual to use it, because they do not want to consider 
the money wasted ('sunk cost' effects), or because they perceive the product as being of higher quality (Cohen and Dupas 2010, 2).

Cohen and Dupas tested this hypothesis for the provision of insecticide-treated bed nets (ITNs), used to prevent malarial infection. They selected 20 prenatal clinics in Western Kenya. Four clinics were assigned as the control group which would continue charging the standard subsidised price for ITNs - a price higher than any of the other groups. The rest of the clinics were randomly assigned a price at which they could sell ITNs to pregnant women, including five clinics that gave them out for free. Cohen and Dupas then monitored the uptake and usage of the ITNs to see if this was in agreement or disagreement with the hypothesis (Cohen and Dupas 2010, 3, 13).

This intervention thus manipulated the environment of the pregnant women under study in such a way that there was a perceived risk (based on the economic theories mentioned above) that they would become less likely to use an ITN-and less likely to ensure that their children used an ITN-as a result of being randomly assigned to the group where ITNs were given out for free, and thus more likely to catch malaria. These women and children were thereby exposed to a perceived risk of severe harm. In addition, Cohen and Dupas's study employed the invasive procedure of measuring haemoglobin levels in the women who attended the clinics in order to assess which of them in fact needed the ITNs the most. Such influence on the lives of the women involved in the study clearly necessitated serious ethical consideration regarding the way the study was set up and reviewed; for example, the implementation of safeguards to ensure that the study would not continue if it proved to be discouraging ITN use in some groups, and that the women involved consented to having blood samples taken for research purposes.

Essentially, anyone who engages in human subjects research has a responsibility to proceed according to certain ethical guidelines, and this includes economists pursuing such research in the field or the laboratory. Luckily for them, biomedical scientists and psychologists have been engaging in human subjects research for long enough to have developed various rules of practice. For academics, guidelines are laid down by their university. ${ }^{3}$ Economists working for private companies on

\footnotetext{
${ }^{3}$ The University of Toronto, for example, has an Ethics Review Office which provides information regarding guidelines and practices for human subjects research. There are several Research Ethics Boards which are responsible for the ethical review of all such research, although primary responsibility for ensuring that research is carried out in an ethical manner falls to the researcher (Ethics Review Office 2007).
} 
the other hand-who have traditionally implemented and evaluated a large proportion of social experiments in the United States (Greenberg, et al. 1999, 166) - have a responsibility to ensure that those companies have similar ethical rules in place. ${ }^{4}$

The claim that economists engaging in human subjects research have a responsibility to adhere to certain ethical standards does not seem to be one that many would dispute. In what follows, however, I will argue that accepting this claim should also lead one to accept that analogous ethical responsibilities extend across the economics profession.

\section{ECONOMIC INTERVENTIONS AND EXPERIMENTS ON HUMAN SUBJECTS}

One reason why it appears to be inconsistent to accept that economic experiments involving human subjects should be conducted in accordance with ethical standards, but at the same time deny that this holds for other economic interventions, is that many economic interventions arguably constitute experiments. If economic interventions are indeed experiments, then they are experiments involving the human beings that are part of the economy in question. Thus, prima facie, those engaging in such interventions are experimenting on a human population, and should therefore follow analogous ethical procedures to those that guide smaller scale human subjects research. As Iain Chalmers puts it, "selectively designating some [social] interventions as "experiments" [...] ignores the reality that policy makers and practitioners are experimenting on other people most of the time" (Chalmers 2003, 30). ${ }^{5}$

Support for the idea that some economic interventions can rightly be considered experiments can be found in the writing of a number of economists: Alfred Eichner, for example, suggests that whenever economic theories are turned into policies we can consider the implementation of the policy a test of the theory, "but with society itself as the test subject" (Eichner 1983, 210); Milton Friedman too believed that policy implementation can constitute an experiment on an economy (sometimes, even, a crucial experiment) (Friedman and Schwartz 1963, 687-688); George DeMartino claims that during the economic

\footnotetext{
${ }^{4}$ In some countries the government will have a policy statement on human subjects research that should help privately employed economists to do this; see, for example, Panel on Research Ethics 2010.

${ }^{5}$ Chalmers in turn attributes this idea to Campbell (1969).
} 
transition of formerly socialist Central and Eastern Europe, the rapid reforms enacted by economists "subjected countries to economic experimentation" (DeMartino 2011, 9); and Dani Rodrik suggests that macro-development economists are coming to realise the importance of an experimental approach, taking China as an example of a country that has implemented macroeconomic interventions in an explicitly experimental manner (Rodrik 2009, 40, 43).

The plausibility or significance of my initial claim that some largescale economic interventions constitute experiments on a human population can be undermined, however, by arguments that most-or even all-economic interventions lack certain essential features of experimentation. Firstly, one might argue that economic interventions cannot in fact ever constitute experiments because they appear to lack controlled experimental conditions. Secondly, one might argue that even if Rodrik and the other economists discussed above are correct that some large-scale economic interventions constitute experiments, this will not be the case for the vast majority of cases. This is because whilst experiments are essentially epistemically-orientated-i.e., interventions on a system with the specific aim of improving knowledge of that system-economic interventions are usually primarily designed to produce a desired change in an economy.

I will address these two objections in turn. I will argue that the first is incorrect because the elements of control lacking in economic interventions are not in fact defining features of experimentation, and that, even if they were, their lack does not obviate the need for ethical concern in this domain. I will support this latter claim with a more detailed analysis of the features of human subjects research that engender an obligation to adhere to ethical standards. This more detailed analysis will in turn help me to deal with the second objection.

\section{Experimental control}

Unlike most laboratory or field experiments, when economy-wide interventions are implemented one cannot observe a control system to which the new policies are not applied. This in turn means that it is difficult to conclude that any other changes in the economy are the result of the intervention, rather than the influence of background effects (which will always be many and varied). Neither, of course, is it possible to have a random assignment of different policies in the economy-wide case. The absence of these methods of experimental 
control might lead some to believe that such interventions cannot constitute experiments, particularly because random allocation often appears to be taken as a defining feature of social experiments (see, for example, Greenberg, et al. 1999, 157; Orr 1999, 10).

However, the use of a control group or randomised allocation are features that make an experiment a good experiment, rather than necessary features for something to count as an experiment simpliciter. Experimental control is a matter of degree. In any science it will be easier to secure adequate experimental control in some cases than others, and "the experimentalist can never, not even in principle, exhaustively demonstrate that no disturbing effects are present" (Galison 1987, 3). Looking more closely at randomisation, we should note that this technique is actually only used in experiments in order to avoid the disturbing effects of 'selection bias' (see Chalmers 2003, 29). ${ }^{6}$ Thus, the absence of random allocation does not prevent something from being an experiment; rather, it makes an experiment's results vulnerable to selection bias. Experimental use of a control group, on the other hand, is not the only way an experimentalist can try to isolate background effects.

Peter Galison's exploration of Cavendish's experiments to measure the effects of gravity provides a useful point of comparison here. Just as it is impossible to have a control system when conducting an economywide intervention, it was not possible for Cavendish to observe a control system where the effects of gravity were not in play. Cavendish instead pursued experimental control in two ways: firstly, by constructing his apparatus in such a way that the disturbing effect of any change in temperature was blocked (by shutting his device in a room and operating it by remote); and secondly, by measuring and calculating features of the background to subtract from his observations as necessary (Galison 1987, 2-3).

When implementing economic policies, analogous attempts at experimental control can be made: firstly, by implementing one new policy at a time rather than, say, five; secondly, by measuring or calculating any background features of the economy that have a known effect on the system. These measures can help economists to assess economy-wide interventions by comparing them to counterfactual

\footnotetext{
${ }^{6}$ Selection bias results when the different behaviours of two experimental systems that are being compared result from systematic differences between them, rather than the different experimental interventions made.
} 
scenarios rather than actual control groups (see Ravallion 2008, 25). This method will obviously be far less able to secure a level of control adequate to ensure that experimental results are informative, but this is a difference of degree, not of kind. Furthermore, even if each individual economic intervention is insufficient to prove or disprove a hypothesis, the accumulation of evidence from many such experiments from many countries over many years can be used by econometricians as a more or less convincing test of economic theory.

I do not believe, therefore, that the impossibility of employing a control group or randomisation gives us reason to hold that large-scale economic interventions cannot count as experiments on a population. Rather these missing features just give us reason to believe that economy-wide interventions can only ever constitute experiments with very significant and unavoidable flaws in terms of internal validityexperiments for which we should be very cautious in drawing any conclusions.

In any case, the absence of these elements of control in economic interventions is irrelevant to whether such work should be held to similar ethical standards as human subjects research. This is because such controls are not the only features of human subjects research that necessitate ethical concern, and thus their absence is not something that will obviate the need for such concern in economic interventions. In order to explain this claim in more detail, I will now discuss the features of human subjects research that give rise to ethical concerns.

\section{Ethically problematic features of human subjects research}

The use of certain types of experimental control can engender specific ethical concerns in human subjects research. The introduction of randomisation in medical trials, for example, resulted in worries that investigators were violating their duty to act in the best interests of the patients involved and led to the development of the principle of 'clinical equipoise' to indicate when the use of randomised allocation is ethically acceptable (see Freedman 1987). The use of a control group in human subjects research, on the other hand, gives rise to particular questions of justice if participants may be benefitted or disadvantaged in morally important ways depending on which group they are assigned to. Therefore the use of control groups calls for particular forms of monitoring, designed to ensure that the experiment does not continue 
beyond the stage where it can be reasonably concluded that one group is receiving significantly greater benefits than the other.

The absence of a control group or randomisation in an economic intervention does, therefore, give us reason to believe that some ethical concerns analogous to those found in human subjects research will probably not arise here. However, such experimental controls are not the only, or most obvious, features of human subjects research that give rise to ethical questions, as I will now attempt to detail. ${ }^{7}$

Perhaps the strongest cause for concern in human subjects research is that such experiments may potentially-or even certainly-harm the participants. Compounding this risk is the fact that experiments are likely to involve scientific theory that is unproven, making their effects on the human subjects involved (whether beneficial or deleterious) uncertain. Whether or not harm is perceived to be likely, experiments have an impact on participants and researchers must therefore show respect for the autonomy of potential subjects by seeking their consent. For consent to be meaningful it must be informed (subjects must understand the goals of the study, what participation involves, and what the risks are), voluntary (free from manipulation and domination), and ongoing (see, e.g., Panel on Research Ethics 2010, 27). Acquisition of voluntary consent can clearly be problematic when financial incentives are offered for participation. An additional complicating factor in the acquisition of meaningful consent is the asymmetry of power between researcher and subject. Researchers will be at an advantage in terms of their knowledge of the area of research, and are likely to rely on their claimed expertise in the field to gain the trust of participants.

Now, whether or not economic interventions instantiate standard features of experimental control, they clearly share these other ethically problematic features of human subjects research-briefly: possible harm, uncertain effects, potential for undermining human autonomy, and asymmetries of power-and thus give rise to analogous concerns. To start with, large-scale economic interventions may potentially-or even, often, certainly-harm the human beings that will be affected by them. Economic policies can lead people to lose their jobs, their homes, and their ability to provide for themselves and their families; they can result in deprivation, starvation, poor health and death.

\footnotetext{
${ }^{7}$ This list-which is by no means intended to be exhaustive-builds on and adds to briefer comments made by Norman Daniels in his discussion of clinical research ethics and health sector reform $(2006,447)$. Daniels's work has had a significant influence on this paper, as will become apparent in later sections.
} 
In some cases economists will be able to calculate the probability of such outcomes with some degree of confidence. However, because the applicability of economic theory to real-world economies and the exact effects of economic policies are in general unproven, in many cases it will not even be possible to assess the likelihood that particular harms will result from an economic intervention, or to predict the magnitude of any harms or benefits that are expected to result.

Even putting the issue of such obvious harms to one side, large-scale economic interventions can affect individuals in ways that undermine or neglect their autonomy: economists, through their policies, "introduce and restrict liberties and freedoms, incentives, rewards, punishments, and risk; they affect incomes, careers, entitlements" (DeMartino 2011,4). Autonomy can be undermined further by the offer of economic incentives for acquiescence. For example, when international financial institutions "provide not just advice but also the material resources that the client state requires to meet basic needs, retain or restore credit, and achieve other vital objectives" (DeMartino 2011, 51), this can undermine individual autonomy by weakening a society's capacity for collective self-determination. And finally, economic policies are formulated and proposed by professional economists whose claimed expertise in a field that is opaque to most of those affected engenders trust in their recommendations. Those affected by policies will in general be at a disadvantage relative to the economists who formulate them-both in terms of their knowledge of economic theory and their influence on policymakers-which means that economic advisors occupy a position of power that can potentially be exploited.

\section{The goals of experiment and economic intervention}

With this analysis of the ethically problematic features of human subjects research in hand, I shall now return to the second objection identified above: that most economic interventions are essentially concerned with producing change, not knowledge. This objection is in a sense more successful than the first, because epistemic-orientation is undeniably an essential aspect of experimentation. Because most economic interventions do not have knowledge generation as their primary purpose they will not constitute experiments after all and, one might conclude, my analogy will therefore only have succeeded in suggesting that ethical concerns arise in the minority of economic interventions that are explicitly experimental. 
However, the detailed analysis of the previous section shows that the analogy between human subjects research and economic intervention stands despite this difference in goals. Even economic interventions that are not primarily concerned with knowledge generation will share at least some of the ethically problematic features identified in the previous section, and thus will still give rise to analogous ethical concerns. I will illustrate this with an example.

Imagine a hypothetical scenario in which Cohen and Dupas do not conduct their study and instead the government of Kenya decides-on the advice of economists - to adopt a new policy whereby ITNs will now be available for free, in the firm belief that this will encourage uptake. Economists and policymakers are so convinced that this intervention will be successful that they do not put any systems in place to monitor the actual effects of the policy, and have no intention of using the intervention to improve their knowledge.

In this hypothetical case-as in Cohen and Dupas's study-it is possible that the $100 \%$ subsidy would undermine the objective of ensuring that ITNs are used by those who need them the most, because economists have underestimated the importance of positive pricing's selection and sunk cost effects, and public perceptions of price as an indicator of quality. The hypothetical national policy would, in addition, place thousands more individuals in a situation of potentially greater risk than the field study because the goal of producing change rather than knowledge discourages policymakers from engaging in monitoring that would indicate if the policy is causing harm (and being prepared to intervene if so). This hypothetical economic intervention therefore calls for a number of ethical guidelines analogous to, but if anything even stronger than, those that would apply to Cohen and Dupas's field experiment, despite the fact that the imagined intervention fails to constitute an experiment.

\section{WHAT DOES THIS MEAN FOR ECONOMISTS?}

Even if it is accepted that large-scale economic interventions share many of the features that engender ethical concerns in human subjects research, and therefore acknowledged that such interventions should be implemented according to analogous ethical guidelines, must one accept that it is economists who have a responsibility to ensure that this is the case? Can one still argue that economists only need provide objective, value-free advice on how to attain an end chosen by the policymaker, 
and that it is the responsibility of the latter to ensure that ethical guidelines are followed? And what about economists who are engaged solely in research or education, and who do not advise any policymakers-do they need to concern themselves with any standards of ethical practice?

I think that the above discussion undermines the claim that economic policy advice can be value-free, because the means-ends distinction can no longer be seen to divide positive questions regarding economic policy formulation from value-laden ones. In Cohen and Dupas's experiment, it was not just the end that they were pursuing (experimental evidence regarding an economic hypothesis) that could raise ethical questions, but also the means (i.e., the experimental method) by which they pursued that end. Analogously, it is not only the end of economic intervention (the achievement of a given economic outcome) which should be subject to ethical assessment, but also the means by which the intervention is conducted. Economists, as the ones called upon by policymakers to suggest the means, therefore need to be involved in ensuring that those means are ethical.

In the next section I shall try to motivate this claim by considering what form ethical guidelines for economic interventions should take and what role economists should play in implementing them. I will do this by drawing on Norman Daniels's recent attempt to apply principles from clinical research ethics to health sector reforms. My discussion will, in addition, suggest that economists engaged in solely research or educational (rather than advisory) roles will also have a responsibility to adhere to certain ethical standards in their work, due to its influence on economic policy.

\section{CLINICAL RESEARCH ETHICS}

In his recent discussions of health system transformation, Daniels argues that health sector reforms "constitute social experiments on a population". Therefore, "the rationale for proactively evaluating clinical experimentation on human subjects also applies to these social experiments". This proactive evaluation will involve "ethical and scientific review before [the reforms] are implemented and ethical and scientific monitoring and evaluation afterwards" (Daniels 2006, 447). If clinical research ethics can teach us a lesson in health sector reform, 
then it seems that it may also be informative in the realm of large-scale economic intervention. ${ }^{8}$

Daniels identifies three main elements of the ethical and scientific review of clinical research which should also apply to health sector reforms: assessment of objectives, assessment of the suitability of the measures to the pursuit of the objectives, and proper governance (Daniels 2006, 447). He suggests that an interdisciplinary team including policy makers, academics and civil society groups should be involved in this review (Daniels 2006, 449; emphasis added). I will discuss each of these elements in turn to see what they suggest about the role economists should play in the ethical formulation and implementation of economic policies.

\section{Objectives}

As is often pointed out, economic objectives (ends) are usually selected by policymakers and politicians, with economists called on to offer advice regarding the means of pursuing those ends. The assessment of those objectives thus seems to be the element of ethical review which is most likely to fall outside the purview of economists.

This is not entirely so, however. For a start, one can dispute the claim that economists are rarely asked to advise policymakers on the selection of goals (Blaug 1992, 129). Refusing to offer such advice is one way for economists to escape some of the ethical responsibilities that arise in this domain, but even then there will be cases where economists have a responsibility to condemn the authentic objectives of governments or policymakers as unethical. In cases where economic policies are sought in the pursuit of unquestionably immoral objectives-say a government was looking for an efficient way to starve the opposition and enrich their family members-an economist surely has an ethical and professional obligation not to offer advice on ways to achieve this. Thus, the assessment of objectives can be the ethical responsibility of economists after all.

\footnotetext{
${ }^{8}$ In fact, the examples that Daniels gives of unsuccessful health reforms that should have been, but were not, subject to ethical review-the introduction of user fees and expansion of the private health sector in developing countries (Daniels 2006, 447) also constitute economic reforms, and were presumably influenced by economic arguments as much as biomedical ones.
} 


\section{Assessment of means}

Once the (ethically acceptable) goals of economic intervention have been agreed upon, means for pursuing those ends need to be chosen. In choosing these means, the evidence that any proposed measures will lead to the desired objective must be examined; practical plans for implementing policies must be devised (Daniels 2008, 270-271); and consideration must be given as to whether there are other (desirable or undesirable) consequences that could result from pursuing the goals of the intervention in any given way. It is here that economists' involvement in the ethical review of interventions will be much more significant.

Economic research is vital for providing evidence that particular economic policies are likely to promote certain economic results. The economic advisors in each case have primary ethical responsibility for ensuring that the evidence they draw on is as reliable as possible, and is not presented as being more conclusive than it really is. Foreseeable risks should be clearly identified. In some cases, when evidence regarding the efficacy of policies for attaining a given objective is lacking, economists could request that they be allowed to first conduct laboratory or field experiments. Such experiments, as I have discussed above, also raise ethical concerns. However, when there are perceived risks from implementing a given economic policy it is surely preferable to first implement it on a smaller rather than a larger scale if possible, and the presence of a control group means that harms and benefits arising from that policy may be identified more easily (and faster).

To return to the example I have been using, the results of Cohen and Dupas's study in fact suggested that women who received free ITNs were no less likely to use them than women who paid a positive price. Furthermore, charging a positive price for ITNs significantly reduced uptake (Cohen and Dupas 2010, 1). Although the small scale of this field experiment creates some problems regarding the external validity of the results, they can still be taken as some evidence that implementing a free distribution policy across Kenya may not put citizens at risk by discouraging use after all, and that failing to implement this policy may well be harming citizens by discouraging the uptake of ITNs.

It is in the assessment of means that purely research economists have ethical responsibilities too. Our body of economic knowledge and theory is a product of the economics profession as a whole, and the 
entire community therefore has a responsibility to take heed of certain ethical requirements. Any economic research which is available in the public domain has the potential to influence policy makers, whether directly or through the advice of other economists. The tentative and unproven nature of most economic hypotheses should therefore be clearly stated, with economists ensuring that they do not make unwarranted claims regarding the predicted consequences of implementing certain economic policies, or the applicability of their economic models to real-world economies. ${ }^{9}$

These requirements can be seen as addressing the possibility of harm, uncertainty and imbalance of power concerns that I identified earlier. As David Colander points out, those not familiar with economic modelling will often have "an elevated view" of the insights it provides, which means that such models can be used inappropriately. Colander suggests that economic modellers should therefore "see themselves as having an ethical responsibility to make the limitations of their models clear to others when they see their models being misused by others in ways that could cause harm to those other people or to society" (Colander 2010, 421-422). Economists involved in teaching have a duty to ensure that their students are made aware of such ethical responsibilities.

Martin Ravallion too emphasises the influence of economic research on policy, in particular in development settings where policymaking "draws on accumulated knowledge built up in large part from published research findings". The realm of publishing comes with its own ethical dilemmas. Difficulty in acquiring funding can mean that relevant research does not get published, conservative publication biases favour papers that confirm received views, and there is a tendency to focus on the internal rather than external validity of research findings. All of these factors can affect the achievement of development goals (Ravallion 2008, 25-26). Here again, academic economists who are involved in the publishing sphere have a responsibility to address such ethical problems, whether or not they personally engage in policy advice.

Another ethical standard that should be adhered to in publishing is to clearly state sources of funding in order to make potential biases

\footnotetext{
${ }^{9}$ Eichner argues that we should go so far as to insist that "any argument, before it is passed on to others as part of the cumulative body of economic knowledge, be empirically validated-and that any argument which cannot meet this test be viewed as at best only a tentative hypothesis, if not rejected outright" (Eichner 1983, 240).
} 
identifiable. Academic research as a whole is becoming increasingly dependent on funding from commercial organisations, and there is some reason to believe that this can affect the outcomes of studies. In the biomedical sciences, for example, there is evidence suggesting that clinical researchers are more likely to find positive results when their studies are funded by the pharmaceutical industry (e.g., Lexchin, et al. 2003; Bhandari, et al. 2004). Such concerns led medical journals to require that authors declare any potential conflicts of interest. It is important that economic researchers do likewise. ${ }^{10}$

All the above considerations should help to ensure that economic research and advice is-as far as possible-honest, transparent, and evidence-based. Nevertheless, due to the intrinsic difficulty of acquiring conclusive economic knowledge, economic policies must still be subjected to continuous monitoring and re-evaluation once implemented. Any potential risks that were identified should be carefully watched for. A commitment from economists to such monitoring and evaluation would also help to ensure that the intervention is properly governed. It is governance to which I will now turn.

\section{Governance}

In clinical research, Daniels explains, good governance involves making sure that subjects have given informed consent to their participation in the study and that concern is shown for their welfare. Informed consent is important to ensure that "subjects can affirm the goals of the research and avoid manipulation, deception, or exploitation". Subjects should also be assured that "adequate surveillance of the outcomes, including risks, is done so that harms can be minimised or benefits optimised" (Daniels 2008, 271). Ethical review of health sector reforms, Daniels argues, should have analogous aspects of governance.

Actually getting every affected individual to give informed consent to health sector or economic reform would simply be impossible. Daniels suggests that when health sector reforms are implemented by democratically accountable agencies, the analogous role to informed

\footnotetext{
${ }^{10}$ In an interesting parallel, Mark Friedberg, Bernard Saffran, Tammy Stinson, Wendy Nelson, and Charles Bennett, find evidence that pharmaceutical industry sponsored economic analyses of cost-effectiveness regarding oncology drugs are less likely to report unfavourable findings (Friedberg, et al. 1989, 1453). Since I wrote this piece, the American Economic Association has adopted more stringent principles of disclosure for conflicts of interest, and now urges economists to apply them in all their activities: www.aeaweb.org/PDF_files/PR/AEA_Adopts_Extensions_to_Principles_for_Author_Disclosure_01-05-12.pdf
} 
consent can be played by "democratic oversight of the reform process". When the institution imposing the reform is not democratically elected, securing anything resembling informed consent will be difficult. This is a particular risk in cases where "powerful external agencies offer large incentives and are not themselves held accountable for the reforms they impose". In such cases, efforts must be made to improve accountability and "empower civic society" (Daniels 2008, 271-272).

Daniels's comments again suggest that policies forced upon struggling economies by non-democratic agencies such as the IMF and the World Bank in return for aid are highly morally problematic because they undermine a society's powers of collective self-determination (even when the countries in question are democratically governed). Increasing the local public accountability of such organisations is thus a particularly important way to protect individual autonomy and provide recourse if the economic policies they proscribe prove harmful. Mark Weisbrot and Dean Baker argue that improving the accountability of International Financial Institutions will have the added bonus of increasing their effectiveness and efficiency, and identify four principles of accountability that can be used to monitor the economic policies they propose: well specified goals prior to implementation; evaluations during implementation to see if the country is on course to satisfy these goals (and, where it is not, a clear indication of why this is the case); wide public availability of any reports to ensure citizens of the country in question are kept fully informed; and identification of the economists and their supervisors who are responsible for the policy design and recommendation (Weisbrot and Baker 2004, 2).

Amanda Wolf's work on the principle of prior informed consentwhich she examines through an investigation of the role it plays in two international trade treaties-might also help us figure out what consent could involve on an economy-wide scale. Informed consent, according to Wolf, is "procedurally principled by disclosure, comprehension, noncoercion, competence, and consent" (Wolf 2000, 503). These elements will be interpreted differently depending on context. In the economic case they likely require economists to ensure that a proper risk assessment-detailing hazards, expected results, and the probability of unintended consequences-of the intervention is completed before it is carried out; that the expected implications of the policy are publicised and explained to those who stand to be affected; and that some form of consultation is carried out in which citizens have the opportunity to 
influence the decision without incurring significant costs, and without being subject to manipulation. One clear implication is that economists have an ethical and professional responsibility not to give advice in favour of controversial or unproven economic policies when those interventions will be implemented by authoritarian regimes. As well as being imposed without any plausible form of consent, such interventions have the potential to do extreme harm to a powerless population, with no guarantee that their effects will be monitored or risks assessed. ${ }^{11}$

Even when informed consent is given it is necessary to continue to manage risks through the course of a social intervention if harm is to be minimised (Wolf 2000, 499). In order to show adequate ethical concern for the population being affected by an economic policy, we should follow Daniels's suggestion that ethical review "be both proactive and ongoing, relying on monitoring and evaluation to make sure that the risks to a population are understood and can be minimised by the timely modification of reforms" (Daniels 2008, 271). We should recognise that reforms in pursuit of worthy societal goals are complicated, that it can take time for changes to take effect, and that things may get worse before they get better. In all of this, though, there should be an understanding of what risks and harms to the interests of the population involved can be considered acceptable.

Plans should be in place to implement alternative policies should the monitoring of interventions suggest that the results of the policy are unacceptable. In this respect, economists would do well to follow Colander's suggestion and acknowledge that rather than involving direct application of economic theory to real-world problems-what he terms the 'economics of control' model-economic policy making really is (and ought to be) a case of 'muddling through'. This latter trial and error approach-in which economic theory is just one of many inputs into decision making-seems much more likely to engender the flexibility and humility that will ensure unsuccessful policies are modified before they do too much harm (see Colander 2003, 197, 202, 208).

Economists can also show concern for those affected by economic policies through a willingness to learn from mistakes. Ignorance, incompetence, or reluctance to properly assess the results of economic

\footnotetext{
${ }^{11}$ Unfortunately this is an ethical imperative that some economists have ignored. See Friedman's letter to General Pinochet (reprinted in Friedman and Friedman 1998, 591-594). I will not here attempt to answer the question of whether it could ever be morally acceptable for economists to give advice to authoritarian regimes.
} 
interventions could well be partly responsible for the trend in development economics for "trying the same thing over and over again, despite a long record of previous failures" (Cohen and Easterly 2009, 21). Repeated implementation of economic policies that past experience has shown may do more harm than good shows a distinct lack of concern for those who stand to be affected.

Ravallion, in a paper on the importance of evaluation in development economics, agrees that "too little evaluative research on development effectiveness gets done" (Ravallion 2008, 3). In part this is due to significant practical and logistical difficulties in conducting evaluations of what will often be long term and diffuse impacts of economic interventions. There is also, however, the problem that such evaluations are a public good and current researchers may not take the benefits that will accrue to future practitioners into account when deciding how much time and effort to spend on them. Ravallion suggests that institutional support for evaluations is therefore important (Ravallion 2008, 5-6); economic researchers will presumably play a crucial role in pressing for such support.

\section{CONCLUSION}

Those who hold economics to be an objective science devoid of ethical concerns, and who claim that economic research and advice can therefore be value-free provided that the means-ends distinction is maintained, are wrong. I have discussed a number of ways in which ethical considerations should enter into economic practice. Economists themselves have a responsibility to further develop the necessary ethical guidelines for their profession, and to encourage the relevant values through active discussion and training (particularly if they do not want to risk having their academic freedom limited by the powers of an external agency that is instead assigned with such a duty). This is another area in which academic economists will find that they possess ethical responsibilities, to ensure that their students-our future economists-are made to consider the ethical questions faced by the profession, such as have been discussed in this paper. ${ }^{12}$ To paraphrase a line that Nobel Prize winning economist Trygve Haavelmo wrote over sixty years ago: Should we expect any less of economists, if their work is

\footnotetext{
${ }^{12}$ Perhaps, for example, professors should ensure that the economics department of which they are a member has mandatory courses in economic ethics.
} 
to be the basis for economic policy upon which may depend the general economic welfare of billions of people? (see Haavelmo 1944, 115).

\section{REFERENCES}

Banerjee, Abhijit, and Esther Duflo. 2009. The experimental approach to development economics. Annual Review of Economics, 1: 151-178.

Bhandari, Mohit, Jason W. Busse, Dianne Jackowski, Victor M. Montori, Holger Shünemann, Shiela Sprague, Derek Mears, Emil H. Schemtisch, Dianne HeelsAnsdell, and P. J. Devereaux. 2004. Association between industry funding and statistically significant pro-industry findings in medical and surgical randomised trials. Canadian Medical Association Journal, 170 (4): 477-480.

Blaug, Mark. 1992. The methodology of economics: or how economists explain. Cambridge: Cambridge University Press.

Campbell, Donald T. 1969. Reforms as experiments. American Psychologist, 24 (4): 409-429.

Chalmers, Iain. 2003. Trying to do more good than harm in policy and practice: the role of rigorous, transparent, up-to-date evaluations. The Annals of the American Academy of Political and Social Science, 589 (1): 22-40.

Cohen, Jessica, and Pascaline Dupas. 2010. Free distribution or cost sharing? Evidence from a randomised malaria prevention experiment. Quarterly Journal of Economics, 125 (1): 1-45.

Cohen, Jessica, and William Easterly. 2009. Introduction: Thinking big versus thinking small. In What works in development? Thinking big and thinking small, eds. Jessica Cohen, and William Easterly. Washington (DC): Brookings Institution Press, 1-23.

Colander, David. 2003. Muddling through and policy analysis. New Zealand Economic Papers, 37 (2): 197-215.

Colander, David. 2010. The economics profession, the financial crisis, and method. Journal of Economic Methodology, 17 (4): 419-427.

Daniels, Norman. 2006. Toward ethical review of health system transformations. American Journal of Public Health, 96 (3): 447-451.

Daniels, Norman. 2008. Just health: meeting health needs fairly. Cambridge: Cambridge University Press.

DeMartino, George F. 2011. The economist's oath. Oxford: Oxford University Press.

Eichner, Alfred. 1983. Why economics is not yet a science. In Why economics is not yet a science, ed. Alfred Eichner. Armonk (NY): M. E. Sharpe Inc., 205-241.

Ethics Review Office. 2007. Guidelines and practices manual for research involving human subjects, Version 1.0. University of Toronto Website.

http://www.research.utoronto.ca/wp-content/uploads/2009/03/ERO_Guidelines_Manual-2007.pdf (accessed April 2012).

Ferber, Robert, and Werner Z. Hirsch. 1978. Social experimentation and economic policy: a survey. Journal of Economic Literature, 16 (4): 1379-1414.

Freedman, Benjamin. 1987. Equipoise and the ethics of clinical research. The New England Journal of Medicine, 317 (3): 141-145.

Friedberg, Mark, Bernard Saffran, Tammy J. Stinson, Wendy Nelson, and Charles L. Bennett. 1999. Evaluation of conflict of interest in economic analyses of new drugs used in oncology. Journal of the American Medical Association, 282 (15): 1453-1457. 
Friedman, Milton, and Rose Friedman. 1998. Two lucky people: memoirs. Chicago: University of Chicago Press.

Friedman, Milton, and Anna Schwartz. 1963. A monetary history of the United States 1867-1960. Princeton: Princeton University Press.

Galison, Peter. 1987. How experiments end. Chicago: University of Chicago Press.

Greenberg, David, Mark Shroder, and Matthew Onstott. 1999. The social experiment market. The Journal of Economic Perspectives, 13 (3): 157-172.

Haavelmo, Trygve. 1944. The probability approach in econometrics. Econometrica, 12 (supplement): iii-vi, 1-115.

Hausman, Daniel M., and Michael S. McPherson. 2006. Economic analysis, moral philosophy, and public policy. Cambridge: Cambridge University Press.

Lexchin, Joel, Lisa A. Bero, Benjamin Djulbegovic, and Otavio Clark. 2003. Pharmaceutical industry sponsorship and research outcome and quality: systematic review. British Medical Journal, 326: 1167-1170.

Orr, Larry. 1999. Social experiments: evaluating public programs with experimental methods. Thousand Oaks (CA): Sage Publications Inc.

Panel on Research Ethics. 2010. Tri-council policy statement: ethical conduct for research involving humans (TCPS 2). Government of Canada Website. http://www.pre.ethics.gc.ca/pdf/eng/tcps2/TCPS_2FINAL_Web.pdf (accessed April 2012).

Pinstrup-Andersen, Per. 2005. Ethics and economic policy for the food system. American Journal of Agricultural Economics, 87 (5): 1097-1112.

Ravallion, Martin. 2008. Evaluation in the practice of development. Policy Research Working Paper, No. 4547. World Bank Development Research Group, Washington, DC.

Rodrik, Dani. 2009. The new development economics: we shall experiment, but how shall we learn? In What works in development? Thinking big and thinking small, eds. Jessica Cohen, and William Easterly. Washington (DC): Brookings Institution Press, 24-47.

Roth, Alvin E. 1993. The early history of experimental economics. Journal of the History of Economic Thought, 15 (2): 184-209.

Weisbrot, Mark, and Dean Baker. 2004. Applying economics to economists: good governance at the international financial institutions. CEPR Briefing Paper. Center for Economic and Policy Research, Washington, DC.

http://www.cepr.net/documents/publications/ifi_2004_07.pdf (accessed April 2012).

Wolf, Amanda. 2000. Informed consent: a negotiated formula for trade in risky organisms and chemicals. International Negotiation, 5 (3): 485-521.

Megan Blomfield is a PhD candidate at the University of Bristol (UK). Her current research focuses on questions of global justice that are raised by the problem of climate change. Her paper "Global common resources and the just distribution of emission shares" is forthcoming in The Journal of Political Philosophy.

Contact e-mail:<mb3586@bris.ac.uk> 